\title{
Erratum
}

\section{Erratum: Butkovich et al., "Transgenic Mice Expressing Human $\alpha$-Synuclein in Noradrenergic Neurons Develop Locus Ceruleus Pathology and Nonmotor Features of Parkinson's Disease”}

In the article "Transgenic Mice Expressing Human $\alpha$-Synuclein in Noradrenergic Neurons Develop Locus Ceruleus Pathology and Nonmotor Features of Parkinson's Disease,” by Laura M. Butkovich, Madelyn C. Houser, Termpanit Chalermpalanupap, Kirsten A. Porter-Stransky, Alexa F. Iannitelli, Jake S. Boles, Grace M. Lloyd, Alexandra S. Coomes, Lori N. Eidson, Maria Elizabeth De Sousa Rodrigues, Danielle L. Oliver, Sean D. Kelly, Jianjun Chang, Nora Bengoa-Vergniory, Richard Wade-Martins, Benoit I. Giasson, Valerie Joers, David Weinshenker, and Malú Gámez Tansey, which appeared on pages 7559-7576 of the September 23, 2020 issue, because of a production error, the spelling of the major brainstem noradrenergic nucleus was changed in the title and throughout the manuscript from the canonical "Locus Coeruleus" to the less common "Locus Ceruleus." The online version has been corrected.

DOI: 10.1523/JNEUROSCI.2726-20.2020 